\title{
Chronic obstructive pulmonary disease pathways as a tool to improve appropriateness in Internal Medicine Departments
}

\author{
Francesco Ventrella, ${ }^{1}$ Franco Mastroianni, ${ }^{2}$ Massimo Errico ${ }^{2,3}$ \\ ${ }^{1} \mathrm{SC}$ Medicina Interna, Presidio Ospedaliero G. Tatarella, Cerignola (FG); ${ }^{2} \mathrm{SC}$ Geriatria, Ospedale Generale Regionale F. Miulli, \\ Acquaviva delle Fonti (BA); ${ }^{3} \mathrm{SC}$ Medicina Interna, Ospedale Generale Regionale F. Miulli, Acquaviva delle Fonti (BA), Italy
}

\begin{abstract}
In recent decades, in the medical field, criteria and methods of decision-making have radically changed, going from an environment dominated by opinions and knowledge transmitted from experts to a context of evidence-based medicine, that finds its practical realization in the drafting of guidelines (GL). However, GL have a poor implementation in the real world for several factors. In the field of chronic obstructive pulmonary disease (COPD), there are already many GL, international, national, regional and by specific scientific societies. This multiplicity, while it responds to the legitimate needs to respect the diversity of interpretation of the available scientific data, on the other hand, however, can be an element of confusion for physicians. In this varied scenery we have tried to create some new tools, easy and quick to use, in order to improve the local application of existing GL on COPD, by planning a limited number of pathways in the management of acute exacerbation of COPD, which focus on the fundamental diagnostic and therapeutic aspects, as a tool to improve appropriateness in Internal Medicine Departments. These pathways, reported on individual sheets, which can be distributed to medical personnel of wards/units involved in the care of patients with COPD (First Aid, Internal Medicine, Geriatrics, Pulmonology, Intensive Respiratory Care Unit, Resuscitation), are useful to support the physician in the decision-making process and help you to resolve any disputes.
\end{abstract}

\section{Introduction}

Criteria and methods of decision-making in the medical field have radically changed in recent decades: they changed from an environment dominated by opinions and knowledge transmitted from experts to a context of evidence based medicine (EBM). EBM finds its practical realization in the drafting of guidelines (GL), to support the decision-making processes in patient care.

Among the different definitions of the GL, published in the scientific literature, ${ }^{1}$ the oldest and most

Correspondence: Francesco Ventrella, via Garibaldi 23, 76017

San Ferdinando di Puglia (BT), Italy.

E-mail: f.ventrella@tiscali.it

Key words: Chronic obstructive pulmonary disease; guidelines; appropriateness; oxygen; non-invasive ventilation.

See online Appendix for Figures.

Received for publication: 14 November 2013.

Revision received: 19 December 2013.

Accepted for publication: 26 December 2013.

This work is licensed under a Creative Commons Attribution NonCommercial 3.0 License (CC BY-NC 3.0).

CCopyright F. Ventrella et al., 2015

Licensee PAGEPress, Italy

Italian Journal of Medicine 2015; 9:96-108

doi:10.4081/itjm.2014.448 widely quoted is the definition of the Institute of Medicine: as systematically developed statements to assist practitioner and patient decisions about appropriate health care for specific clinical circumstances. ${ }^{2,3}$

However, the publication of the GL has often poor practical impact in the concrete improvement of general clinical practice. ${ }^{4-8}$

Several factors prevent the implementation of GL in the real world: i) too much test (several pages) in relation to time available for physicians; ii) multiplicity of GL on the same subject by different organizations and scientific societies; iii) mode of presentation not always effective (a lot of text, small print); iv) high complexity of recommendations (with different levels of evidence and strength of recommendations); v) limited accessibility (publication in journals or sites are not always used to all).

In the field of chronic obstructive pulmonary disease (COPD), there are already many GL: at international level (GOLD 2014, ${ }^{9}$ ACP-ACCP-ATS-ERS $2011^{10}$ ), at national level (USA ICSI 2013, ${ }^{11}$ British NICE 2010, ${ }^{12}$ Canadian CTS 2007, ${ }^{13}$ Italian AGENAS $2009^{14}$ and AIMAR-AIPO-SIMER-AGENAS-2011 ${ }^{15}$ ), at regional level (Tuscany 20116), in addition to some documents of Consensus Conferences, such as those developed by the Italian Federation of Associations of Hospital Doctors on Internal Medicine (FADOI) 2012. ${ }^{17}$

This multiplicity, while it responds to the legitimate needs to respect the diversity of interpretation of the available scientific data, on the other hand, however, can be an element of confusion for physicians. 
In this varied scenery we have tried to create some new tools, easy and quick to use, in order to improve the local application of existing GL on COPD.

A useful Appendix is available online to summarize these new tools.

We used the model of the diagnostic-therapeutic protocol in order to obtain a link between GL and improvement of care quality, thus contributing to the achievement of the effectiveness and appropriateness objectives of the GL. ${ }^{18,19}$

So, we published ${ }^{20}$ a diagnostic-therapeutic protocol (PDT) for the internal medicine patients with acute exacerbation of chronic obstructive pulmonary disease: from the moment they arrive at the hospital until discharge, to be applied in the Puglia region. This PDT has obtained the endorsement of FADOI Puglia, SIMI Puglia and Basilicata (Italian Society of Internal Medicine), SIGG Puglia and Basilicata (Italian Society of Gerontology and Geriatrics), SIGOT Appulo-Lucana (Italian Society of Geriatric Hospital and Territorial) and A.Re.S. Puglia (Regional Health Agency). ${ }^{20}$

From this PDT were extracted a limited number of pathways in the management of acute exacerbation of COPD (AECOPD), which focus on the fundamental diagnostic aspects that have to be assessed and monitored, on the information to be collected in a systematic, structured and continuous basis, on the procedures for the proper setting of the therapy, on the useful indicators to check the actual achievement of clinical objectives.

These pathways, reported on individual sheets, which can be distributed to medical personnel of wards/units involved in the care of patients with COPD (First Aid, Internal Medicine, Geriatrics, Pulmonology, Intensive Respiratory Care Unit, Resuscitation), are useful to support the physician in the decision-making process and help you to resolve any disputes.

\section{Management of chronic obstructive pulmonary disease in Emergency Department}

Figure 1 shows, in summary, the diagnostic algorithm to be implemented in the emergency room immediately after the arrival of the patient from the territory, to formulate the correct diagnosis and identify the most appropriate care setting for the individual clinical case. To do this we propose the use of the following three simple dichotomous clinical scores, to be applied progressively: i) observational sign and symptom index (OSSI) score: it helps to make the diagnosis of AECOPD, excluding alternative diagnoses, along with history and physical examination; ii) decisional observation objective rescue (DOOR) score: it contributes to the definition of the setting of care, i.e., hospital or home; iii) WHERE score: in case of hospitalization, it directs the choice of the most appropriate department among the general wards (Internal
Medicine or Geriatrics), the Semi-Intensive Respiratory Care Unit or Critical Area of Internal Medicine [where to implement non-invasive ventilation (NIV)] and the Intensive Care Unit [where to implement the invasive mechanical ventilation (IMV)].

When a patient with suspected AECOPD reaches the Emergency Department we suggest the following path (Figure 2). After the history and physical examination, some urgent laboratory and instrumental exams must be carried out: blood count, blood urea, creatinine, sodium, potassium, glucose, serum glutamic oxaloacetic transaminase, serum glutamic pyruvic transaminase, bilirubin, activated partial thromboplastin time, international normalized ratio, NT pro-BNP, D-dimer, serum albumin, arterial blood gas (ABG), electrocardiogram, chest X-ray. Then, in order to strengthen the diagnosis of AECOPD, we can use the OSSI score. The OSSI score provides three major items (increase in sputum, increase of dyspnea, purulent sputum) and six minor items (upper respiratory tract infection in the past 5 days; fever not from other known causes; increased cough; increased wheezing; heart rate (HR) $>20 \%$ compared to baseline; respiratory rate (RR) $>20 \%$ compared to baseline). If at least two major items of the OSSI score or one major + one minor exist, the diagnosis of AECOPD is confirmed; if not, alternative diagnoses should be considered. If the diagnosis is AECOPD, DOOR score helps to take a decision whether to treat patient at home or in hospital. The DOOR score provides 13 items: i) respiratory failure; ii) acidosis; iii) sudden and marked symptoms; iv) dyspnea at rest; v) significant comorbidities; vi) poor response to outpatient therapy; vii) important feeding problems; viii) important disorders of sleep; ix) worsening of pre-existing hypoxemia; $\mathrm{x}$ ) worsening of pre-existing hypercapnia; xi) neuro-psychological impairment; xii) inappropriate home support; xiii) diagnostic doubt.

If there is none of these (minor acute exacerbation), the patient can be treated at home; if at least one of these occurs, the patient must be hospitalized.

In patients hospitalized, the WHERE score helps to identify the appropriate care setting.

It provides seven items: i) progressive dyspnea; ii) confused state or lethargy or coma; iii) $\mathrm{PO}_{2}<40$ $\mathrm{mmHg}$ persistent/worsening with $\mathrm{O}_{2}$ or NIV; iv) $\mathrm{PCO}_{2}>60 \mathrm{mmHg}$ or worsening with $\mathrm{O}_{2}$ or NIV; v) $\mathrm{pH}<7.35$ with $\mathrm{O}_{2}$ or NIV; vi) indication for invasive mechanical ventilation; vii) hemodynamic instability/need for vasopressors.

If there is none of these, the patient may be admitted to a general ward (Internal Medicine or Geriatrics); if at least one of these exists, the patient must be allocated in Semi-Intensive Respiratory Care Unit or Critical Area of Internal Medicine for NIV or in Intensive Care Unit for IMV (see below). 
Appendix Figure 1 shows the algorithm to be applied to patients with AECOPD with DOOR score $=$ zero (minor acute exacerbation), that can be managed at home by the general practitioner or in Short Intensive Observation in the Emergency Department. The algorithm provides several therapeutic steps, to be applied in succession, each followed by a clinical control at a distance of a few hours. The outcome may be the complete stabilization of the patient with the prescription of long-term treatment or, in case of lack of improvement, the hospitalization. This algorithm is also in line with the recommended approach by Respiratory Section of the Italian Society of General Medicine (SIMG). ${ }^{21}$

\section{ALGORITHM}

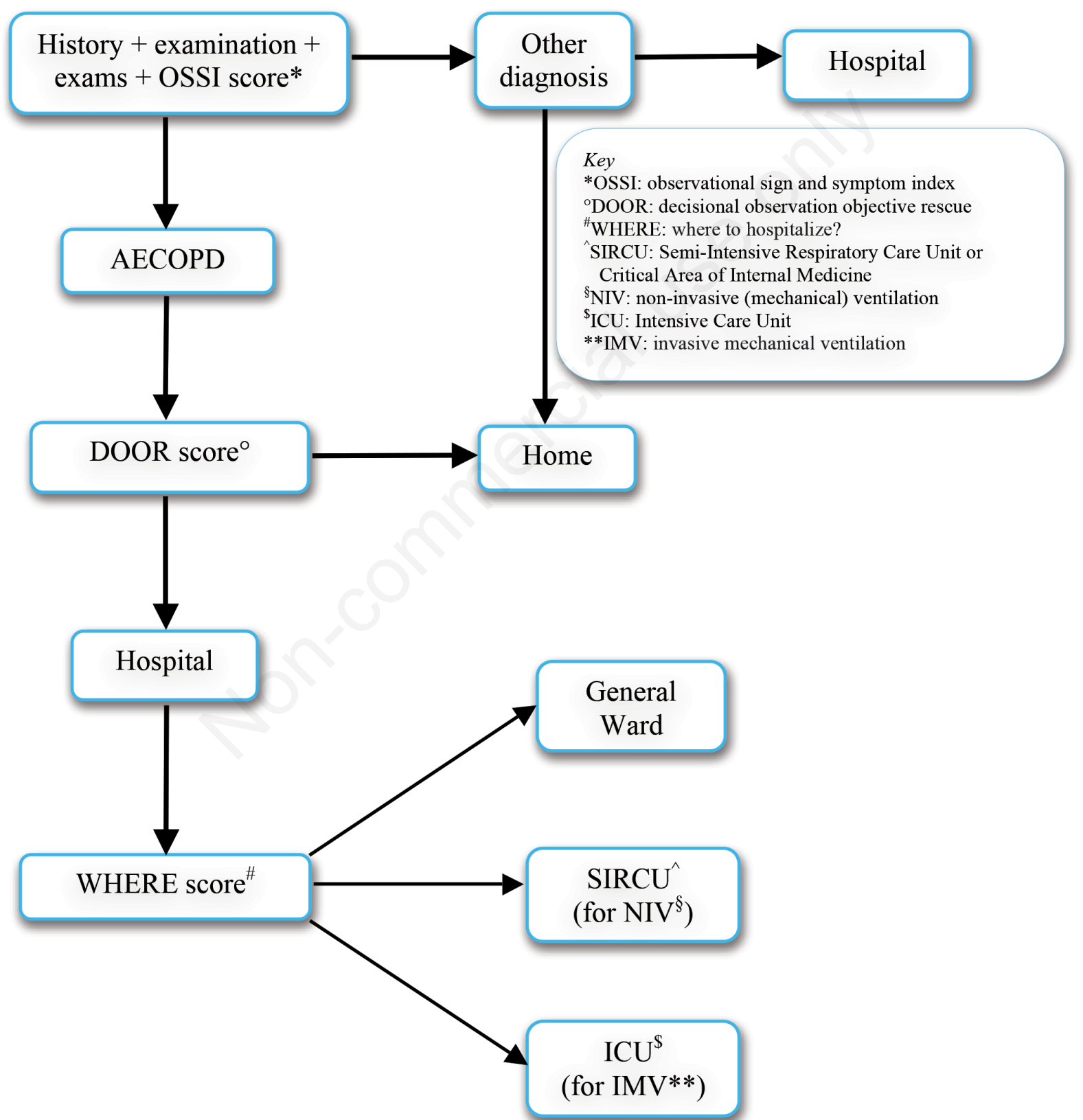

Figure 1. Algorithm of patients with suspected acute exacerbation of chronic obstructive pulmonary disease (AECOPD) in Emergency Department. 


\section{History + examination}

2. Urgent exams: blood count, blood urea, creatinine, sodium, potassium, glucose, SGOT, SGPT, bilirubin, aPTT, INR, NT pro-BNP, D-dimer, serum albumin, arterial blood gas, EKG, chest X-ray

\section{OSSI score}

\begin{tabular}{|l|l|}
\hline \multicolumn{2}{|c|}{ Reference or fact } \\
\hline \multirow{3}{*}{ A } & Increase in sputum \\
\hline & Increase in dyspnea \\
\hline & Purulent sputum \\
\hline \multirow{4}{*}{$\mathrm{B}$} & Upper respiratory tract infection in the past 5 days \\
\hline & Fever not from other known cause \\
\hline & Increased cough \\
\hline & Increased wheezing \\
\hline & HR $>20 \%$ compared to baseline (if detectable) \\
\hline & RR $>20 \%$ compared to baseline (if detectable) \\
\hline
\end{tabular}

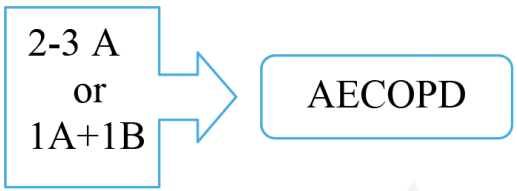

If not AECOPD consider alternative diagnoses

1 (history + examination $)+2$ (laboratory and instrumental exams $)+3($ OSSI score $)=$ DIAGNOSIS

4. DOOR score (to determine whether to admit or discharge home)

\begin{tabular}{|l|}
\hline Respiratory failure? \\
\hline Acidosis? \\
\hline Sudden and marked symptoms? \\
\hline Dyspnea at rest? \\
\hline Significant comorbidities? \\
\hline Poor response to outpatient therapy? \\
\hline Important feeding problems? \\
\hline Important disorders of sleep? \\
\hline Worsening of pre-existing hypoxemia? \\
\hline Worsening of pre-existing hypercapnia? \\
\hline Neuro-psychological impairment? \\
\hline Inappropriate home support? \\
\hline Diagnostic doubt? \\
\hline
\end{tabular}

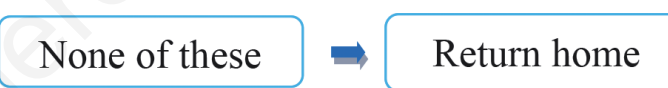

5. WHERE score (where to hospitalize?)

\begin{tabular}{|l|}
\hline Progressive dyspnea? \\
\hline Confused state or lethargy or coma? \\
\hline $\mathrm{PO}_{2}<40 \mathrm{mmHg}$ persistent/worsening with $\mathrm{O}_{2}$ or NIV? \\
\hline $\mathrm{PCO}_{2}>60 \mathrm{mmHg}$ or worsening with $\mathrm{O}_{2}$ or NIV? \\
\hline pH<7.35 with $\mathrm{O}_{2}$ or NIV? \\
\hline Indication for invasive mechanical ventilation? \\
\hline Hemodynamic instability/need for vasopressors? \\
\hline
\end{tabular}

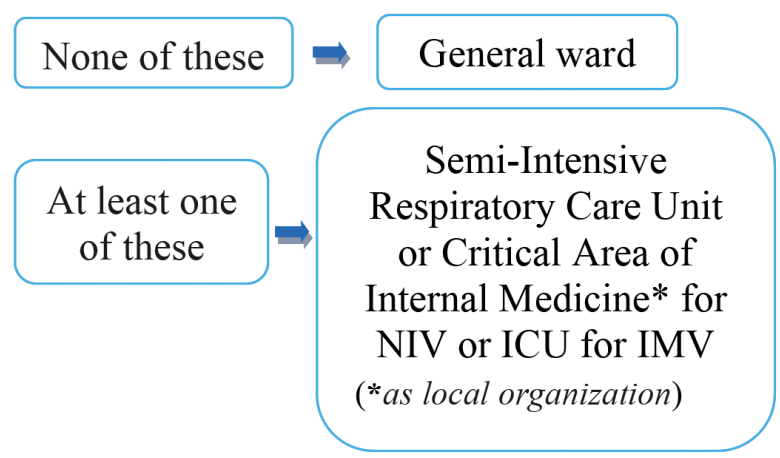

Figure 2. Acute exacerbation of chronic obstructive pulmonary disease (AECOPD): patient management in the Emergency Department. 


\section{Management of chronic obstructive pulmonary disease in Internal Medicine Department}

Appendix Figure 2 shows the therapy that should be established during hospitalization. It is the synthesis of the main guidelines on the management of AECOPD. But it needs some clarification. With regard to bronchodilator therapy, although there are no controlled studies, there is great consensus on the choice of shortacting bronchodilators, $\beta 2$-agonist (SABA) and/or short acting muscarinic antagonists (SAMA). ${ }^{9-17,22,23}$

The administration of short-acting bronchodilators must be of intensive type, every 5-6 h, because their duration of action, in particular for SABA, is only 4-6 h.

For administration, can be used indifferently prebatched spray dispensers, so-called metered dose inhalers (MDI), with or without a spacer, and nebulizers. ${ }^{24}$

The use of the spacer allows, within certain limits, to reduce needs of the patient's cooperation in synchronizing the delivery of the spray dose inhaler with the inspiration and, therefore, makes possible the use of this device also in sparsely uncooperative patient, especially if it has the availability of spacer with mask. The nebulizers do not require cooperation from the patient and therefore are most often used. Should be favored the nebulisers by compressed air or electric; should be avoided, instead, the use of oxygen as propellant gas, because, as it will be explained later, in the moderate or severe exacerbations of COPD, the high-flow oxygen necessary for the nebulization of the drug $(8-10 \mathrm{~L} / \mathrm{min})$, can cause worsening of hypercapnia. ${ }^{25-27}$

In common clinical practice, administration of short-acting bronchodilators every $5-6 \mathrm{~h}$ is easily accomplished during daylight hours, while it is more difficult during the night. And it is during the night that the physiological circadian oscillation of bronchial tone leads to increased bronchoconstriction, with worsening dyspnea ${ }^{28,29}$

Therefore, although there are no controlled clinical trials on this procedure, it is rational to associate the short-acting bronchodilator therapy in repeated doses during daylight hours (at $8 \mathrm{am}, 2 \mathrm{pm}, 8 \mathrm{pm}$ or $7 \mathrm{am}, 1$ $\mathrm{pm}, 7 \mathrm{pm}$ ) with a single dose in the evening (at $11 \mathrm{pm}$ ) of an inhaled bronchodilator long-acting, associated or not with inhaled corticosteroid, through the use of MDI with spacer.

It should be noted, finally, that the early introduction of the use of MDI with spacer also ensures better training of the patient to use the device at home; training that is sometimes overlooked in the daily activities of wards.

The inhaled bronchodilator therapy for 7-10 days is always associated with systemic corticosteroid therapy, which has been shown to improve lung function [forced expiratory volume in the first second (FEV1)] and arterial hypoxemia, ${ }^{30-33}$ reducing risk of early relapse, treatment failure, and length of hospital stay. ${ }^{30,31,34}$

Recently have been recommended shorter cycles of systemic corticosteroid therapy ( 5 days $)^{9}$ compared to traditional 7-14 days. ${ }^{11-13}$

The continuation of systemic steroid therapy beyond two weeks has not shown advantages on acute exacerbation.

Because of the unfavorable risk/benefit ratio, the long-term treatment with systemic steroids ${ }^{9}$ must be avoided. The long-term corticosteroid therapy, when indicated, should be carried out with inhaled corticosteroids, always associated with inhaled bronchodilators.

With regard to antibiotic therapy exists evidence to support the antibiotic-therapy in exacerbations in which there is toning purulent sputum ${ }^{35}$ or when mechanical ventilation is indicated. ${ }^{36}$

As regards the choice of antibiotics, it is useful to proceed to the classification of the individual patient in one of the three risk groups for therapeutic failure, unfavorable outcome and onset of resistance, as indicated in Table 1, which defines, for each group, the characteristics of the patient, the more likely bacterial etiology and then the antibiotics of choice for empirical therapy. ${ }^{37}$

Moreover, in the management of patients with AECOPD we propose a systematic evaluation of thromboembolic risk and of bleeding risk (Appendix Figure 3). For the thromboembolic risk we suggest a score of major reference, the Padua prediction score, that has been proposed and validated in an Italian study ${ }^{38}$ and later also adopted by the American College of Chest Physicians (ACCP) guidelines for estimating the risk of venous thromboembolism in hospitalized medical patients ${ }^{39}$

For bleeding risk, we propose some warnings, reported in Appendix Figure 3B.

\section{Oxygen therapy}

Figure 3 summarizes the procedure of oxygen administration. Oxygen is a drug and, therefore, it is necessary to pay attention to its prescription, specifying the system of administration and dose, i.e., the fraction of inspired oxygen $\left(\mathrm{FiO}_{2}\right)$; the correct determination of $\mathrm{FiO}_{2}$ is essential to avoid the disadvantages of overdosing or underdosing. ${ }^{40}$

The dosage, which varies from case to case, should be adjusted based on arterial oxygen saturation to be achieved in the specific type of patient. While in hypoxemic-normocapnic patients the goal of oxygen therapy is a saturation of $94-98 \%$, in hypoxemic and hypercapnic patients or at risk of hypercapnia, as the patients with COPD are often, the target saturation should be much lower, around $88-92 \%$. Only in the case of persistently normal $\mathrm{PCO}_{2}$, even in the course of oxygen, and in the absence of prior history of respiratory failure treated with pulmonary ventilation, 
you will be able to tend to a saturation of $94-98 \%$. The caution in the target oxygenation of these patients is due to the well known event that a higher dose of $\mathrm{O}_{2}$ can promote hypercapnia up to respiratory acidosis, through different pathophysiological mechanisms: reduction of ventilatory drive, altered ventilation-perfusion ratio (V/Q), Haldane effect, higher density of oxygen than air. ${ }^{25,27,41-43}$

It follows that oxygen therapy in patients with COPD have to be controlled in $\mathrm{FiO}_{2}$ and, in that sense, the best administration of oxygen is obtained with the Venturi masks, ${ }^{22,25,27}$ following the steps indicated in Figure 3.

Venturi masks (ventimask) are systems with a high flow, consisting of a mask and a series of interchangeable valves of different color, each of them must be supplied with a specific minimum flow of oxygen from the centralized system (by 2 to $15 \mathrm{~L} / \mathrm{min}$ ), thus ensuring a specific $\mathrm{FiO}_{2}$ (typically from $24 \%$ to $60 \%$ ). On each colored valve are indicated the $\mathrm{FiO}_{2}$ and the oxygen flow in $\mathrm{L} / \mathrm{min}$.

It should be emphasized that the flow of oxygen recommended for each valve is defined as the minimum flow. The increase of the oxygen flow, above the recommended level for each valve, will result in an increased suction of air into the system and therefore in an increased flow of oxygen-air mixture supplied to the patient, but the $\mathrm{FiO}_{2}$ will always remain the same, as determined by the amplitude of the orifice of the fitting. ${ }^{25,27}$

The British Thoracic Society Guidelines ${ }^{25}$ recommend that in patients with COPD and respiratory rate $>30$ breaths $/ \mathrm{min}$, the flow rate of oxygen, to be used for the specific $\mathrm{FiO}_{2}$, should be increased by $50 \%$, so as to determine, as specified above, an increase in the total gas flow provided to the patient, but always with the same $\mathrm{FiO}_{2}$.

In some patients the ventimask may be poorly tolerated (claustrophobia); on these it should be replaced by a nasal cannula as soon as possible.

The nasal cannulas have some advantages: greater comfort, no claustrophobic feeling, allow the patient to eat, take medication and talk during use. However, they have important limitations: reduction in oxygena-

Table 1. Stratification of patients with acute exacerbation of chronic obstructive pulmonary disease into severity classes for the antibiotic treatment and the microorganism potentially involved in each group.

\begin{tabular}{|c|c|c|c|}
\hline Group & Patients' features & Possible pathogenic & Treatment options \\
\hline \multicolumn{4}{|l|}{ A } \\
\hline \multirow[t]{5}{*}{ Exacerbation mild or uncomplicated } & Age $\leq 65$ years & H. influenzae & Macrolides (azitro, claritro) \\
\hline & Exacerbations $\leq 4 /$ year & S. pneumoniae & Amoxicillin/clavulanate \\
\hline & FEV $1>50 \%$ of predicted & M. catarrhalis & Oral cephalosporins* \\
\hline & & C. pneumoniae & \\
\hline & & Virus & $\begin{array}{l}\text { If allergy to these or failure: } \\
\text { levofloxacin or moxifloxacin }\end{array}$ \\
\hline \multicolumn{4}{|l|}{$\mathrm{B}$} \\
\hline \multirow{3}{*}{$\begin{array}{l}\text { Exacerbation moderate-to-severe } \\
\text { (no risk factors for } \\
\text { P. aeruginosa) }\end{array}$} & Age $>65$ years & Group A + & Amoxicillin/clavulanate \\
\hline & FEV $130-50 \%$ of predicted & Enterobacteriaceae & Levofloxacin, moxifloxacin $^{\circ}$ \\
\hline & Acute exacerbation $>4 /$ year & K. pneumoniae & Cefotaxime, ceftriaxone \\
\hline & Important comorbidities & E. coli & \\
\hline & & Proteus & \\
\hline & & Enterobacter & \\
\hline \multicolumn{4}{|l|}{$\mathrm{C}$} \\
\hline Exacerbation moderate-to-severe & Previous detection of & Gruppo B + & Piperacillin/tazobactam or \\
\hline (with risk factors for & P. aeruginosa & P. aeruginosa & cefepime \\
\hline \multirow[t]{3}{*}{ P. aeruginosa) } & FEV $1<30 \%$ of predicted & & + \\
\hline & Chronic corticosteroid therapy & & Ciprofloxacin ${ }^{\#}$ or \\
\hline & Antibiotic therapy more than 4 times/year & & $\begin{array}{l}\text { levofloxacin }{ }^{\wedge} \text { or } \\
\text { aminoglycoside }\end{array}$ \\
\hline
\end{tabular}

Risk factors for $P$. aeruginosa:

- Severe impairment of lung function (FEV1<30\% of predicted)

- Recent hospitalization

- No. exacerbations of COPD>3/year

- Corticosteroid therapy in the last 3 months

- Cycle of antibiotic therapy in the last 3 months

- Presence of bronchiectasis

- Previous isolation of P. aeruginosa (during exacerbation or less)

*Use high doses (e.g., cefditoren $400 \mathrm{mg}$ bid); ${ }^{\circ}$ to be used only when antibiotics commonly recommended for the initial treatment are deemed inappropriate or have failed. In Italy is only available for oral; "to be evaluated based on local epidemiological; ${ }^{\wedge}$ to be evaluated based on local epidemiology. The effective dose against $P$. aeruginosa is $750 \mathrm{mg}$ (not for sale in Italy). FEV1, forced expiratory volume in the first second; COPD, chronic obstructive pulmonary disease. 


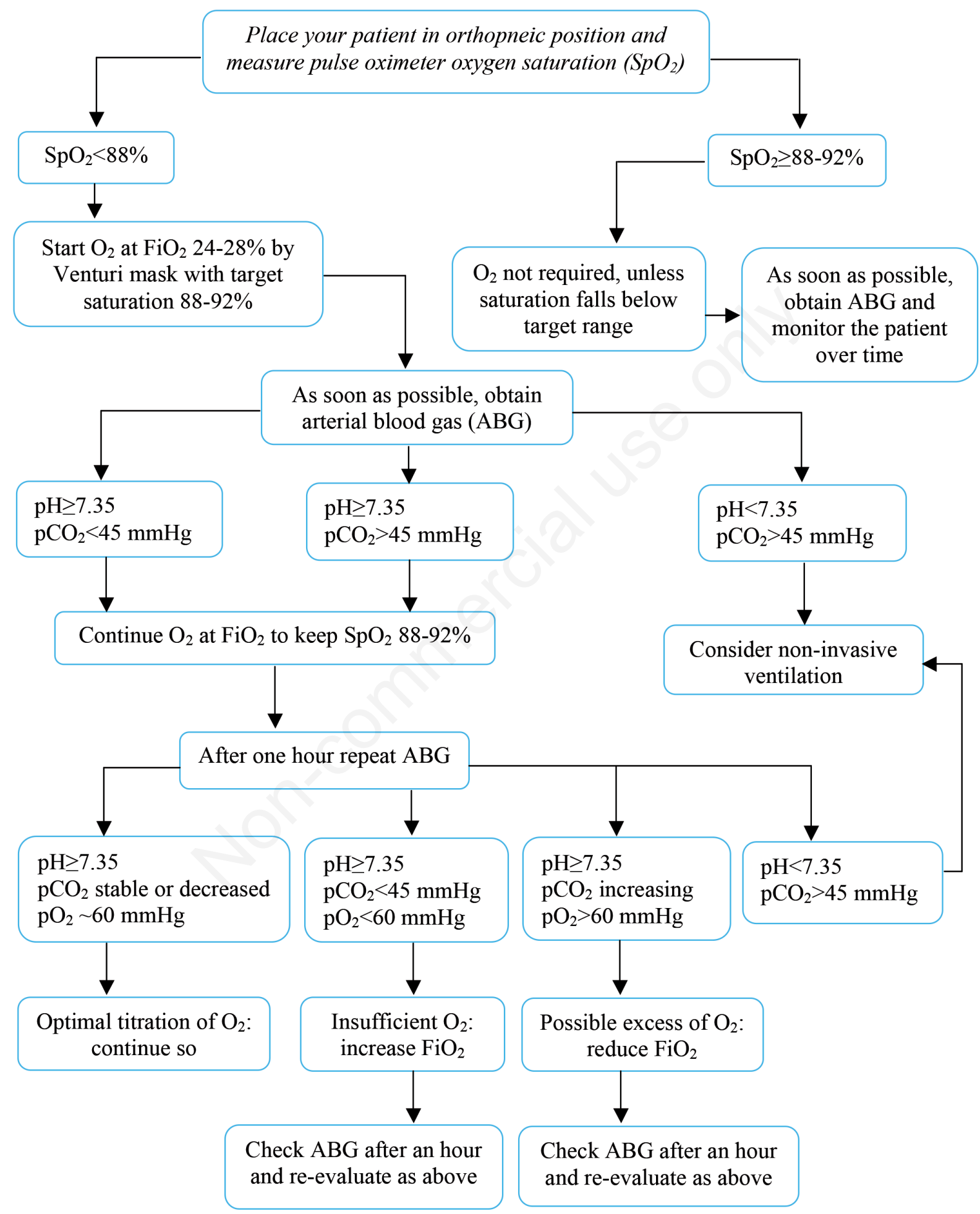

Figure 3. Oxygen therapy in patients with acute exacerbation of chronic obstructive pulmonary disease (AECOPD) (patients at high risk of hypercapnia). 
tion if the patient breathes mainly with the mouth, ineffectiveness in case of severe nasal congestion, but also less accuracy in the determination of $\mathrm{FiO}_{2}$ compared to the Venturi mask.

The need to ensure a controlled oxygen therapy often clashes with the mode of execution of the aerosol therapy to administer the inhaled bronchodilators. ${ }^{25-27}$

In most wards, as well as in ambulances, the aerosol is carried out using oxygen at high flows as nebulizing gas (with $\mathrm{FiO}_{2}$ up to $60 \%$ ). This, as mentioned above, can favor the hypercapnic acidosis, which often appears quite early, even within 15 minutes from the beginning of the high flow of $\mathrm{O}_{2}$. In cases where there is not any of the alternatives with respect to oxygen-nebulizers to administration of inhaled bronchodilators (use of electric nebulizers or compressed air nebulizers or metered-dose inhaler $M D I$ with spacer), a useful tip is to use the aerosol up to a maximum of $6 \mathrm{~min}$, time which usually ensures the administration of most of the dose of the drug while it limits to the maximum the risk of hypercapnia, which usually appears within 15 min. ${ }^{25}$

\section{Non-invasive ventilation}

Non-invasive ventilation (Figure 4) can be used in various forms of respiratory failure, and has proved to be particularly effective in the patient with respiratory failure from AECOPD, with the great advantage, compared to invasive ventilation, to avoid complications due to the process of endotracheal intubation (EI). ${ }^{44-47}$

Initially introduced and tested within the Intensive Care Units (ICUs), NIV was later also used outside the ICUs, in semi-intensive setting or even in the common wards, with consequent greater accessibility to a wider population of patients. ${ }^{48-50}$

The use of NIV outside the ICUs is the major advantage of this ventilatory technique, with the possibility of intervention at an early stage, for levels of respiratory acidosis mild or mild to moderate, for which there is no indication for invasive mechanical ventilation in ICU.
There are extensive experimental demonstrations in the literature of the great utility of NIV in patients with respiratory failure due to COPD, outside the ICUs in the ordinary wards of hospitalization, with rates of mortality and EI lower than the standard medical therapy alone, especially in cases with mild respiratory acidosis or mild-to-moderate treated early. ${ }^{51-60}$

From this experimental evidence derived the awareness that NIV can be used with safety and efficacy, even outside the ICUs, in areas adequately monitored in ordinary wards, with medical staff having necessary technical skills, ${ }^{48,49,61-69}$ ensuring a success rates on average of up to $80-85 \%$ and reduction both in the mortality and in the length of hospital stay. ${ }^{9}$

The use of NIV compulsorily requires the adoption of a protocol regarding indications, absolute and relative contraindications, modes of ventilation, clinicalinstrumental monitoring and weaning.

It is also desirable to provide an internal quality control, with one or more indicators, a reference standard, and by means of a collection of treated patients' data and their outcome. Finally do not forget the need to be clearly aware of your own limitations, how far you can push yourself and when to call instead the resuscitator.

The space available for this article does not allow you to analyze the physiopathological conditions of NIV and the many details of implementation of the different possible ventilation modes, for which reference should be made to the rich literature on the subject. ${ }^{9,20,64-70}$

NIV is a growing reality in the departments of Italian Internal Medicine. In our region, Puglia, the use of this technique is rapidly spreading in hospitals, albeit with different levels of organization and complexity, as shown in a recent survey carried out by the FADOI Puglia, the results of which are summarized in Table 2.

These data show that in approximately one-fifth (23.7\%) of Internal Medicine Departments of Puglia, continuous positive airway pressure (CPAP) and NIV are technologies currently used in full autonomy; to these we will add $15.8 \%$ of Departments who currently use only the CPAP independently. Most departments $(55.3 \%)$ often engage in these techniques, but they still

Table 2. Survey on the use of continuous positive airway pressure and non-invasive ventilation in Internal Medicine Departments of the Puglia region (year 2013).

Degree of adhesion to the survey

38 Internal Medicine Departments of Puglia

(of 40 contacted) responded to the survey (95\% adherence)

\begin{tabular}{lcc}
\hline Usage level & No. departments & Rate (\%) \\
\hline Use of CPAP and NIV in complete autonomy & $9 / 38$ & 23.7 \\
\hline Use of only CPAP in complete autonomy & $6 / 38$ & 15.8 \\
\hline Use of NIV and CPAP with the help of intensivists or pulmonologists & $21 / 38$ & 55.3 \\
\hline No use of NIV & $8 / 38$ & 21
\end{tabular}

CPAP, continuous positive airway pressure; NIV, non-invasive ventilation. 
Assess the following parameters

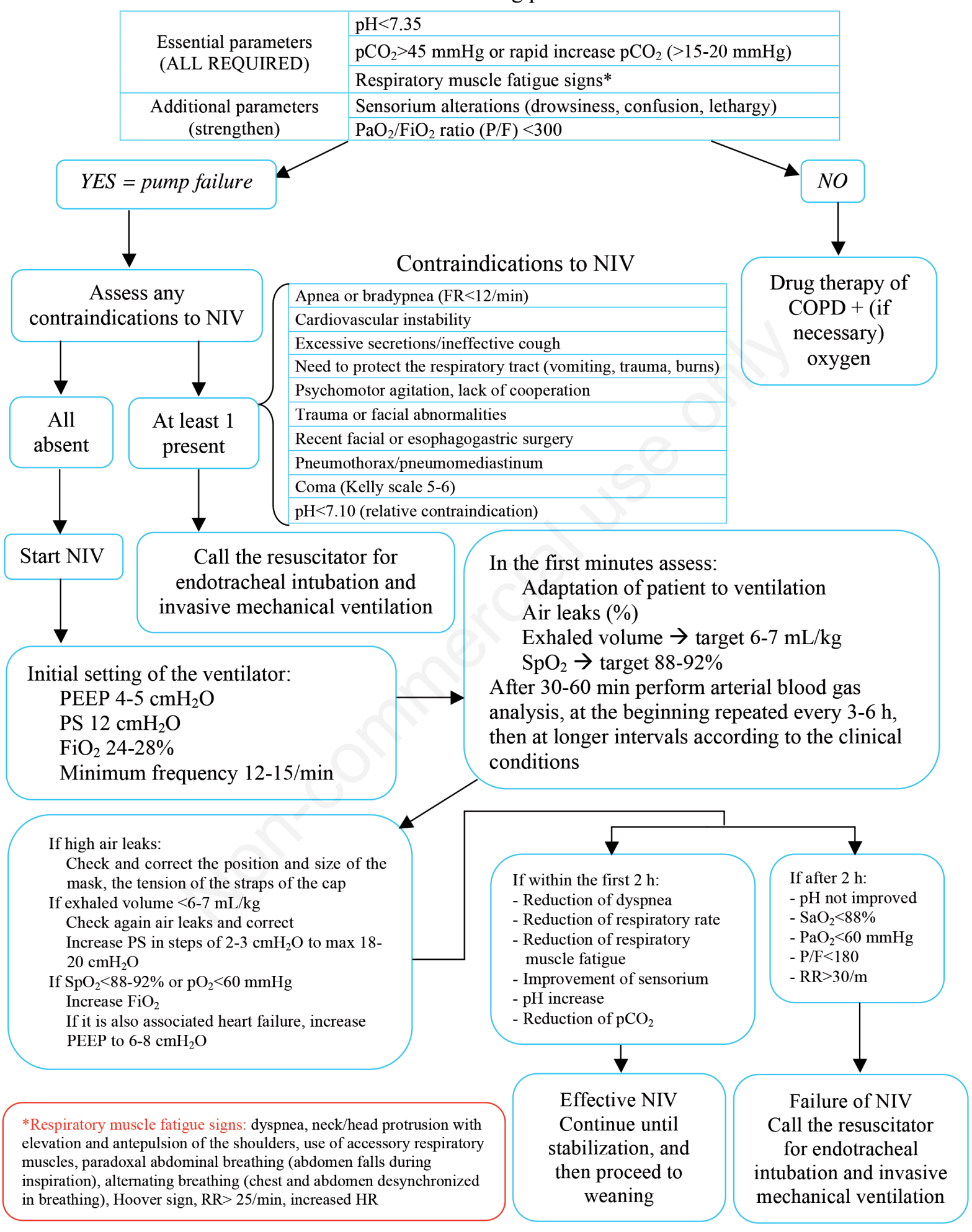

Figure 4. Patient with acute exacerbation of chronic obstructive pulmonary disease (AECOPD) to be considered for non-invasive ventilation (NIV). 
depend on the support or advice of intensivists or pulmonologists. Therefore, given the widespread interest in this technique from the internists, it is desirable that the Scientific Societies of Internal Medicine, primarily the FADOI, ensure a strong commitment to raising and training, aimed at fostering a greater and more widespread dissemination and indipendent management of NIV in almost all Internal Medicine Departments.

Figure 4 shows the precise indications to NIV: the most relevant is the reduction of the $\mathrm{pH}$ below 7.35, associated with hypercapnia, which is the typical expression of respiratory deficiency of the ventilatory pump (pump failure), due to respiratory muscle fatigue. It should be emphasized that, in patients with COPD, high values of $\mathrm{PCO}_{2}$ with normal $\mathrm{pH}(>7.35)$ never represent an indication to NIV in acute phase (being usually an expression of a compensated chronic condition).

Of crucial importance is the choice of the right moment to start the NIV. In recent years the scenario of cases and timing of use of NIV have been detailed with greater precision and three different situations have been identified, on a scale of increasing severity in respiratory acidosis and depending on the specific therapeutic target of NIV: ${ }^{67}$ i) when applied to patients with early respiratory acidosis, that is to say, with a $\mathrm{pH}$ between 7.34 and 7.30, the goal of NIV is to prevent the aggravation of respiratory failure: therapeutic intervention of choice in general wards; ii) when applied to patients with more critical clinical conditions and more advanced acidosis, i.e., with a $\mathrm{pH}$ between 7.29 and 7.25 , the purpose of NIV is to avoid EI; iii) when it is applied to much more severe patients with $\mathrm{pH}<7.25$, NIV is used as an alternative to EI (for which there is already need) for a brief attempt to achieve improvements to ward off invasive ventilation in ICU.

The most used mode of NIV is pressure support ventilation (PSV), associated with a positive end-expiratory pressure (PEEP). In PSV mode, the ventilator provides a positive pressure of base, of low intensity (for example $5 \mathrm{cmH}_{2} \mathrm{O}$ ), which is present during the expiratory phase (PEEP), to which, in the inspiratory phase, is added a further positive pressure of greater magnitude (e.g., $15 \mathrm{cmH}_{2} \mathrm{O}$ ), which supports the work of the inspiratory muscles (PS).

It is not the aim of this paper a detailed analysis of individual trials in the literature on the results obtained with the NIV in its various fields of application.

It may be useful, however, to those who intend to adopt it in their professional activity, highlighted, in a nutshell, the overall results that can be expected from

it, according to all the studies already cited:

- rate of success of NIV from 65 to $80 \%$ (failure is defined as the death of the patient or the need of EI and invasive ventilation);

- in-hospital mortality ranges from 20 to $33 \%$;

- in $15-28 \%$ of patients who have had an initial pos- itive response to NIV, after more than $48 \mathrm{~h}$, a worsening of respiratory failure may occur requiring EI: so-called late NIV failure;

- the factors that influence the percentages of success or failure of NIV are: i) the etiology of respiratory failure (best results in patients with COPD); ii) the extent of the initial alteration of $\mathrm{pH}$ (greater chance of success if $>7.25$ ); iii) the favorable response of the $\mathrm{pH}$ in the first $1-2 \mathrm{~h}$ of NIV; iv) the overall severity of the clinical picture of the patient, as indicated by APACHE score (greater chance of success if $<20-29$ ); v) comorbidities;

- the age does not seem to be a problematic factor for NIV: in very elderly patients the mortality was not significantly different compared to patients younger than 10 ;

- in patients for whom there is no consensus to EI or there is contraindication to EI, do not intubate status, treated with NIV, the short-term survival is $50 \%$.

\section{Hospital discharge and follow-up}

There are optimal criteria that support the discharge: i) stable clinical improvement (for 12-24 h), documented by: reduction in cough, dyspnea, sputum, regression of fever, etc.; ii) stable improvement (for 12-24 h) of respiratory failure, scored using $\mathrm{ABG}$, with $\mathrm{PO}_{2}>60 \mathrm{mmHg}, \mathrm{P} / \mathrm{F}>300$ and $\mathrm{pH}>7.35$; iii) recovery of skills prior to admission (walking, eating, dressing, etc.); iv) certainty that the patient (or caregiver) has fully understood all about the use of medicines, and has acquired skills in the use of inhaler device and, if nedeed, of oxygen-therapy; v) certainty about the proper organization of home management and subsequent follow-up.

Before the patient is discharged, it is necessary to establish the combined assessment of severity of COPD after resolution of the exacerbation.

Appendix Figure 4 summarizes the steps for the combined assessment of the COPD severity, predicted from the recent GOLD guidelines, ${ }^{9}$ following which it will be possible to set the long-term pharmacological therapy of stable COPD.

This approach provides mandatory integrated assessment of two key issues: i) the extent of the clinical symptoms (outside of exacerbations); ii) the risk of future exacerbations.

The symptomatology is measured using the COPD assessment test (CAT) questionnaire and/or the scale of the modified Medical Research Council (mMRC) dyspnea (Appendix Figure 4A): i) if the CAT score is $<10$ and/or the degree of dyspnea is $<2 \mathrm{mMRC}$ scale, the patient will be classified as low symptom; ii) if the CAT score is $>10$ and/or the degree of dyspnea is $>2$ mMRC scale, the patient will be classified as high symptomatology. 
The risk of exacerbations is measured by reference, on the one hand, to the level of airflow obstruction measured by spirometry (GOLD level I to IV according to the percentage reduction in FEV1 of patient than normal), on the other hand to the number of exacerbations that occurred last year. The patient will be: i) low risk of exacerbation if he/she has a spirometric GOLD level I-II and has had a number of exacerbations in the last 12 months $<2$ without any hospitalization; ii) high risk of exacerbation if he/she has a spirometric GOLD level III-IV and/or has had a number of exacerbations in the last 12 months $\geq 2$ or $\geq 1$ leading to hospital admission.

On the basis of such information it will be possible to identify four different combined levels of severity, identified respectively with the capital letters A, B, C, D.

In those cases where there is an absolute impossibility to carry out the spirometric assessment before discharge, this must be programmed not later than 12 months, on the occasion of the $1^{\text {st }}$ follow-up.

In patients who smoke, before discharge must be adequately assessed the extent of tobacco dependence and willingness to quit smoking. ${ }^{71}$

Appendix Figure 5 shows two short questionnaires that can be simply and quickly administered before discharge.

Depending on the outcome of this assessment you can program an adequate counseling and, if needed, medication, to help the patient to stop smoking. ${ }^{72,73}$

\section{References}

1. Legido-Quigley H, Knai C, Panteli D, et al. Part 1: Overview, conceptual framework and methods. Clinical guidelines: background and overview. In: LegidoQuigley H, Panteli D, Car J, et al., eds. Clinical guidelines for chronic conditions in the European Union. European observatory on health systems and policies a partnership hosted by World Health Organization. Observ Stud Ser 2013;30:1-16.

2. Field MJ, Lohr KN, eds. Clinical practice guidelines: directions for a new program. Washington, DC: Institute of Medicine, National Academy Press; 1990.

3. Field MJ, Lohr KN, eds. Committee on clinical practice guidelines. guidelines for clinical practice: from development to use. Washington, DC: Institute of Medicine, National Academy Press; 1992.

4. Brusamento S, Knai C, Legido-Quigley H, et al. Part 4 Are guidelines in Europe well developed? Are they well implemented? Do they have any impact? A systematic review of the literature. In: Legido-Quigley H, Panteli D, Car J, et al., eds. Clinical guidelines for chronic conditions in the European Union. European observatory on health systems and policies - a partnership hosted by World Health Organization. Observ Stud Ser 2013;30:56-81.

5. Tinelli C, Rezzani C, Biino G, et al. Evaluation of the efficacy of the Italian guidelines on COPD: a cluster randomized trial. Monaldi Arch Chest Dis 2003;59:199-206.
6. Berti E, Casolari L, Grilli R. Governo clinico e lineeguida. In: Grilli R, Taroni F, eds. Il governo clinico. Roma: Il Pensiero Scientifico ed.; 2004. pp 29-50.

7. Chalmers J. Implementation of guidelines for the management of hypertension. Clin Exp Hypertens 1999;21: 647-57.

8. Grol R, Dalhuijsen J, Thomas S, et al. Attributes of clinical guidelines that influence use of guidelines in general practice: observational study. Br Med J 1998;317:858-61.

9. Global Initiative for Chronic Obstructive Lung Disease (GOLD). Global strategy for the diagnosis, management and prevention of COPD - Update 2014. Available from: http://www.goldcopd.org/

10. Qaseem A, Wilt TJ, Weinberger SE, et al. Diagnosis and management of stable chronic obstructive pulmonary disease: a clinical practice guideline update from the American College of Physicians, American College of Chest Physicians, American Thoracic Society and European Respiratory Society. Ann Intern Med 2011;155: 179-91.

11. Anderson B, Conner K, Dunn C, et al. Institute for Clinical System Improvement (ICSI): diagnosis and management od chronic obstructive pulmonary disease (COPD) - Updated March 2013. Available from: https:// www.icsi.org/guidelines_more/

12. National Clinical Guideline Centre. Chronic obstructive pulmonary disease: management of chronic obstructive pulmonary disease in adults in primary and secondary care. London: National Clinical Guideline Centre; 2010. Available from: http://guidance.nice.org.uk/CG101/ Guidance/pdf/English

13. O'Donnel DE, Aaron S, Bourbeau J, et al. Canadian Thoracic Society recommendations for management of COPD - 2077 updated. Can Respir J 2007;14:5B-32B.

14. AGENAS. Broncopneumopatia cronica ostruttiva Linee guida nazionali di riferimento per la prevenzione e la terapia - aggiornamento al 2009. Available from: http://www.pneumonet.it/scientifico/editoriali/linee_gui da_BPCO_2010/BPCO.pdf

15. AIMAR, AIPO, SIMER, AGENAS. La gestione clinica integrata della BPCO. Roma: Ed Burston-Marsteller; 2011.

16. Regione Toscana Linee guida sulla broncopneumopatia cronica ostruttiva (BPCO). Available from: http://www. snlg-iss.it/lgr_toscana_BPCO_2011.

17. Nozzoli C, Fabbri LM, Gensini G, et al. Consensus Conference. Diagnosi, valutazione di gravità e trattamento della broncopneumopatia cronica ostruttiva e delle malattie concomitanti. Ital J Med 2012;6 Suppl:1-33.

18. Istituto Superiore di Sanità - PNLG. Manuale metodologico - Come produrre, diffondere e aggiornare raccomandazioni per la pratica clinica. Milano: Ed. Arti grafiche Passoni; 2002. Available from: http://www. snlg-iss.it/manuale_metodologico_SNLG

19. Berti E, Casolari L, Grilli R. Governo clinico e lineeguida. In: Grilli R, Taroni F, eds. Il governo clinico. Roma: Il Pensiero Scientifico ed.; 2004. pp 29-50.

20. Errico M, Mastroianni F, Ventrella F. Protocollo diagnostico-terapeutico (PDT) del paziente internistico con riacutizzazione di bronco-pneumopatia cronica ostruttiva: dall'arrivo in ospedale alla dimissione. Ital J Med 2013;7 Suppl 5:1-42.

21. Bettoncelli G, Corbetta L. Guida pratica sulla broncopneumopatia cronica ostruttiva (BPCO). Serie Editoriale Disease Management 18. Pisa: Pacini Ed.; 2005. pp 1-58. 
22. Celli BR, MacNee W. Standards for the diagnosis and treatment of patients with COPD: a summary of ATS/ERS position paper. Eur Respir J 2004;23:932-46.

23. Belmonte G, Muratori M, Leandri P. et al. Il percorso diagnostico-assistenziale della broncopneumopatia cronica ostruttiva riacutizzata in Medicina Interna. Ital J Med 2011;5:199-214.

24. Turner MO, Patel A, Ginsburg S, et al. Bronchodilator delivery in acute airflow obstruction. A meta-analysis. Arch Intern Med 1997;157:1736-44.

25. O'Driscoll BR, Howard LS, Davison AG, on behalf of the British Thoracic Society. BTS guideline for emergency oxygen use in adult. Patients. Thorax 2008;63:vi1-vi68.

26. Cameron L, Pilcher J, Weatherall M, et al. The risk of serious adverse outcomes associated with hypoxaemia and hyperoxaemia in acute exacerbations of COPD. Postgrad Med J 2012;88:684-9.

27. O'Driscoll R. Emergency oxygen use. BMJ 2012;345: e6856.

28. Sgambato F. BPCO ed insufficienza respiratoria: non solo VEMS e PaO2. In: Sgambato F, Milano L, eds. Gli equilibri in medicina interna - Alla ricerca de "i Fondamentali”. Benevento: Ed. Auxiliatrix; 2013. pp 179-198.

29. Terzano C, Petroianni A, Graziani E. Asma. In: Terzano C, ed. Malattie dell'apparato respiratorio. Milano: Ed. Springer-Verlag; 2006. pp 307-367.

30. Davies L, Angus RM, Calverley PM. Oral corticosteroids in patients admitted to hospital with exacerbations of chronic obstructive pulmonary disease: a prospective randomised controlled trial. Lancet 1999; 354:456-60.

31. Maltais F, Ostinelli J, Bourbeau J, et al. Comparison of nebulized budesonide and oral prednisolone with placebo in the treatment of acute exacerbations of chronic obstructive pulmonary disease: a randomized controlled trial. Am J Respir Crit Care Med 2002;165:698-703.

32. Niewoehner DE, Erbland ML, Deupree RH, et al. Effect of systemic glucocorticoids on exacerbations of chronic obstructive pulmonary disease. Department of Veterans Affairs Cooperative Study Group. N Engl J Med 1999; 340:1941-7.

33. Thompson WH, Nielson CP, Carvalho P. et al. Controlled trial of oral prednisone in outpatients with acute COPD exacerbation. Am J Respir Crit Care Med 1996; 154:407-12.

34. Aaron SD, Vandemheen KL, Hebert P, et al. Outpatient oral prednisone after emergency treatment of chronic obstructive pulmonary disease. N Engl J Med 2003;348: 2618-25.

35. Stockley RA, O'Brien C, Pye A, Hill SL. Relationship of sputum color to nature and outpatient management of acute exacerbations of COPD. Chest 2000;117:1638-45.

36. Woodhead M, Blasi F, Ewig S, et al. Guidelines for the management of adult lower respiratory tract infections. Eur Respir J 2005;26:1138-80.

37. Blasi F, Bulfoni A, Concia E, et al. Attualità nella gestione delle infezioni delle basse vie respiratorie in medicina interna. Ital J Med 2010;4:1-78.

38. Barbar S, Noventa F, Rossetto V, et al. A risk assessment model for the identification of hospitalized medical patients at risk for venous thromboembolism: the Padua Prediction Score. J Thromb Haemost 2010;8:2450-7.

39. Kahn SR, Lim W, Dunn AS, et al. Prevention of VTE in nonsurgical patients antithrombotic therapy and prevention of thrombosis, 9th ed: American College of Chest Physicians Evidence-Based Clinical Practice Guidelines. Chest 2012;141:e195S-e226S.

40. Cameron L, Pilcher J, Weatherall M, et al. The risk of serious adverse outcomes associated with hypoxaemia and hyperoxaemia in acute exacerbations of COPD. Postgrad Med J 2012;88:684-9.

41. Campbell EJM. A method of controlled oxygen administration which reduces the risk of carbon-dioxide retention. Lancet 1960;2:12-4.

42. Johnson JE, Peacock MD, Hayes JA, et al. Forced expiratory flow is reduced by $100 \%$ oxygen in patients with chronic obstructive pulmonary disease. South Med J 1995;88:443-9.

43. Austin MA, Wills KE, Blizzard L, et al. Effect of high flow oxygen on mortality in chronic obstructive pulmonary disease patients in prehospital setting: randomised controlled trial. BMJ 2010;341:c5462.

44. Organised jointly by the American Thoracic Society, the European Respiratory Society, the European Society of Intensive Care Medicine, and the Société de Réanimation de Langue Française, and approved by the ATS Board of Directors. International Consensus Conferences in Intensive Care Medicine: non-invasive positive pressure ventilation in acute respiratory failure. Am J Respir Crit Care Med 2001;163:283-91.

45. British Thoracic Society Standards of Care Committee. BTS guideline - Noninvasive ventilation in acute respiratory failure. Thorax 2002;57:192-211.

46. Chawla Rajesh, Khilnani GC, Suri JC, et al. Guidelines for noninvasive ventilation in acute respiratory failure. Indian J Crit Care Med 2006;10:117-47.

47. Keenan SP, Sinuff T, Burns KE, et al. Canadian Critical Care Trials Group/Canadian Critical Care Society Noninvasive Ventilation Guidelines Group. Clinical practice guidelines for the use of noninvasive positive-pressure ventilation and noninvasive continuous positive airway pressure in the acute care setting. CMAJ 2011;183:E195-214.

48. Elliott MW, Confalonieri M, Nava S. Where to perform noninvasive ventilation? Eur Respir J 2002;19:1159-66.

49. Chiumello D, Conti G, Foti G, et al. Non-invasive ventilation outside the Intensive Care Unit for acute respiratory failure. Minerva Anestesiol 2009;75:459-66.

50. Cabrini L, Monti G, Villa M, et al. Non-invasive ventilation outside the Intensive Care Unit for acute respiratory failure: the perspective of the general ward nurses. Minerva Anestesiol 2009;75:427-33.

51. Lightowler JV, Wedzicha JA, Elliott MW, et al. Non-invasive positive pressure ventilation to treat respiratory failure resulting from exacerbations of chronic obstructive pulmonary disease: Cochrane systematic review and meta-analysis. BMJ 2003;326:185.

52 . Nava S, Hill N. Non-invasive ventilation in acute respiratory failure. Lancet 2009;374:250-9.

53. Plant PK, Owen JL, Elliott MW. Early use of non-invasive ventilation for acute exacerbations of chronic obstructive pulmonary disease on general respiratory wards: a multicentre randomised controlled trial. Lancet 2000;355:1931-5.

54. Ambrosino N, Vagheggini G. Non-invasive ventilation in exacerbations of COPD. Int J Chron Obstruct Pulmon Dis 2007;2:471-6. 
55. Keenan SP, Sinuff T, Cook DJ, Hill N. When is the addition of noninvasive positive pressure ventilation effective in acute exacerbations of COPD? A systematic review. Ann Intern Med 2003;138:861-70.

56. Elliott MW. Non-invasive ventilation in acute exacerbations of chronic obstructive pulmonary disease: a new gold standard? Intensive Care Med 2002;28:1691-4.

57. Scala R, Naldi M, Archinucci I, Coniglio G. Non-invasive positive pressure ventilation in acute hypercapnic respiratory failure: clinical experience of a respiratory ward. Monaldi Arch Chest Dis 2004;61:94-101.

58. Mclaughlin KM, Murray IM, Thain G, Currie GP. Wardbased non-invasive ventilation for hypercapnic exacerbations of COPD: a 'real-life' perspective. Q J Med 2010;103:505-10.

59. Fiorino S, Detotto E, Battilana M, et al. Severe exacerbations of chronic obstructive pulmonary disease: management with noninvasive ventilation on a general medicine ward. Ital J Med 2010;4:173-8.

60. La Regina M, Marinaro A, Scuotri L, et al. Non-invasive mechanical ventilation in internal medicine department: a pilot study. Ital J Med 2013;7:172-8.

61. Brochard L, Mancebo J, Elliott MW. Noninvasive ventilation for acute respiratory failure. Eur Respir J 2002; 19:712-21.

62. Elliott MW. Non-invasive ventilation for acute respiratory disease. Br Med Bull 2004;72:83-97.

63. Elliott MW. Noninvasive ventilation in acute exacerbations of COPD. Eur Respir Rev 2005;14:94,39-42.

64. Crocco F, Ferrari R, Francesconi R, et al. L'insufficienza respiratoria acuta e il suo trattamento precoce mediante CPAP in emergenza. Utilizzo della NIV nel trattamento dell'insufficienza respiratoria acuta in emergenza. Torino: Ed. SIMEU; 2006. Available from: http://www.simeu.it/ formazione/dispensaNIMVSIMEU.pdf

65. Lari F, Giostra F, Bragagni G, Di Battista N. La venti- lazione meccanica non invasiva nell'insufficienza respiratoria acuta: stato dell'arte (I parte). Ital J Med 2009; 3:201-11.

66. Lari F, Giostra F, Bragagni G, Di Battista N. La ventilazione meccanica non invasiva nell'insufficienza respiratoria acuta: stato dell'arte (II parte). Ital J Med 2010;3:6-15.

67. Nava S, Fanfulla S. Ventilazione meccanica non invasiva. Come, quando e perché. Milano: Ed. Springer-Verlag; 2010.

68. Cabrini L, Antonelli M, Savoia G, Landriscina M. Noninvasive ventilation outside of the Intensive Care Unit: an Italian survey. Minerva Anestesiol 2011;77:313-22.

69. Appendini L. Gestione ventilatoria del paziente con BPCO. In: Antonelli M, et al., eds. Ventilazione meccanica invasiva e non invasiva: dalla fisiopatologia alla clinica. Milano: Elsevier; 2012. pp 169-188.

70. Di Battista N, Ferrari R, Giostra F, et al. La ventilazione meccanica non invasiva per il medico d'urgenza. Torino: C.G. Edizioni Medico Scientifiche; 2010.

71. Clavario P. The clinical evaluation of the smoker. Monaldi Arch Chest Dis 2002;58:161-5.

72. Faggiano F, Gelormino E, Mathis F, et al. Commissione Regionale Anti-Tabacco - Cessazione del fumo di tabacco. Linee Guida clinico-organizzative per la Regione Piemonte. Quaderno no. 3. Torino: Ed. Alessandri; maggio 2007. Available from: http://www.cpo.it/it/pubblicazioni/show/cessazione-del-fumo-di-tabacco-lineeguida-clinico-organizzative-per-la-regione-piemonte-qu aderno-n $\% \mathrm{C} 2 \% \mathrm{~B} 0-3 /$

73. Zuccaro P, Amato L, Caraffa G, et al. Istituto Superiore di Sanità. Osservatorio Fumo, Alcol e Droga - Linee guida cliniche per promuovere la cessazione dell'abitudine al fumo. Aggiornamento 2008. Roma: Ed. Centro Stampa De Vittoria; maggio 2008. Available from: http://www. iss.it/ofad 